heart failure: concomitant reduction in beta $_{1}$ - and beta adrenoceptor function related to the degree of heart failure in patients with mitral valve disease. J Am Coll Cardiol 1989;14:323-31.

50. Böhm M, Diet F, Feiler G, Kemkes B, Erdmann E. $\alpha$-Adrenoceptors and $\alpha$-adrenoceptor-mediated positive inotropic effects in failing human myocardium. J Cardiovasc Pharmacol 1988;12:357-64.

51. Bristow MR, Minobe W, Rasmussen R, Hershberger RE, Hoffman BB. Alpha-1 adrenergic receptors in the nonfailing and failing human heart. .J Pharmarol Exp Ther 1988;247: 1039-45.

52. Schmitz W, Kohl C, Neumann J, Scholz H, Scholz J. On the mechanism of positive inotropic effects of alpha-adrenoceptor agonists. Basic Res Cardiol 1989;84(suppl 1):23-33.

53. Brodde O-E, Daul A, Michel-Reher M, Boomsma F, Man in't
Veld AJ, Schlieper P, Michel MC. Agonist-induced desensitization of $\beta$-adrenoceptor function in man. Subtype-selective reduction in $\beta_{1}$ - or $\beta_{2}$-adrenoceptor-mediated physiological effects by xamoterol or procaterol. Circulation 1990;81:914-21.

54. Motomura S, Khamssi M, Zerkowski H-R, Brodde O-E. Is there a receptor reserve for isoprenaline in the human heart? [Abstract]. Eur Heart J 1989;10(suppl):427.

55. Levevre-Borg F, Lorrain J, Lechaire J, Thiry C, Hicks PE, Cavero I. Studies on the mechanisms of the development of tolerance to the hypotensive effects of fenoldopam in rats. $J$ Cardiovasc Pharmacol 1988;11:444-55.

56. Eden RJ, Harvey CA, Hutchinson M, Owen DAA, Parker SG. Characterisation of the tolerance to the cardiovascular effects of SK\&F 101468-A in spontaneously hypertensive rats [Abstract]. Br J Pharmacol 1989;97(suppl):390P.

\title{
How to select a drug for the long-term treatment of chronic heart failure
}

\begin{abstract}
First-line drugs for the treatment of chronic congestive heart failure should produce immediate symptomatic benefit, improve exercise tolerance, and thereby improve the quality of life. They should preferentially be active as monotherapy or at least reduce the need for comedication. The drugs must be safe and well tolerated by patients and change, in the end, the natural history of the disease, so that sudden death will be prevented and life expectancy improves. None of the currently available drugs satisfies all these criteria. Diuretics, digitalis, converting-enzyme inhibitors, and ibopamine come close to the described ideal. (AM HEART J 1990;120:1572-8.)
\end{abstract}

Arie J. Man in 't Veld, MD, PhD Rotterdam, The Netherlands

The question addressed in the title of this article is certainly not new and has, in fact, been discussed repeatedly in several leading editorials in recent years. ${ }^{1-6}$ Apparently the subject is still surrounded by controversies or new developments, particularly in the field of innovations in drug treatment of the disease that are required for frequent reorientation. For many years digoxin and diuretics were the only choices for the treatment of chronic congestive heart failure (CHF). However, even the combination of the two drugs fails to help patients with advanced disease and those who have the most debilitating forms of CHF. The efficacy of digoxin for patients with CHF

From the Department of Internal Medicine I, University Hospital Dijkzigt, Erasmus University Rotterdam.

Reprint requests: Arie J. Man in't Veld, MD, Department of Internal Medicine I, University Hospital Dijkzigt, Erasmus University Rotterdam, Dr. Molewaterplein 40, 3015 GD Rotterdam, The Netherlands.

4/0/23941 who are in sinus rhythm has been disputed for almost 200 years. $^{7}$ However, some recently reported, carefully controlled, randomized, double-blind trials have now shown beyond any doubt that digoxin relieves disability and improves exercise tolerance in CHF, thereby ending, to some extent, this long-lasting discussion. ${ }^{8-12}$

It should be clearly noted that most of the information in this article as well as several considerations for answering the question of how to choose a drug for the treatment of CHF, are from reviews by Packer. ${ }^{5,6}$ These criteria ${ }^{13}$ for choosing a drug for the treatment of CHF will also be applied to the novel, orally active inodilator ibopamine in this article.

\section{DRUGS FOR CHF TREATMENT}

During the past 5 years, more new drugs have been synthesized and evaluated for the treatment of CHF than during the previous 200 years. ${ }^{5}$ More than 80 different orally active compounds have been admin- 
Table I. Oral drugs for the treatment of CHF: Vasodilators

Venodilators
Isosorbide dinitrate
Erythrityl tetranitrate
Pentaerythritol tetranitrate
Isosorbide 5-mononitrate
Molsidomine
Arterial dilators
Hydralazine
Dihydralazine
Endralazine
Cadralazine
Dipyridamole
Minoxidil
Ro 12-4713
Fenoldopam
Pinacidil
L-Dopa
Ibopamine
Calcium antagonists
Verapamil
Nifedipine
Diltiazem
Nicardipine
Nisoldipine
Isradipine
Felodipine
Amlodipine
Nitrendipine
Mixed
Flosequinan

istered to patients with $\mathrm{CHF}$, and more than $30 \mathrm{ad}$ ditional drugs have been tested by the intravenous route. Although some of these new drugs have either directly or indirectly multiple actions on the complex hemodynamic and neurohumoral derangements in heart failure, on the basis of their pharmacodynamic actions, they can be classified as follows: (1) vasodilators (arterial-venous, mixed, including $\alpha$-adrenoreceptor antagonists and calcium antagonists), (2) inotropic agents, (3) $\beta$-adrenoreceptor antagonists (including $\beta$-adrenoreceptor "buffers" or "modulators"), (4) angiotensin-converting enzyme inhibitors, and (5) diuretics.

Some drugs with a combined vasodilator and inotropic action are classified as "inodilators" according to the concept postulated by Opie. ${ }^{14}$ Ibopamine, a prodrug, which is converted into epinine, is one of these inodilators with a combined action on adrenergic and dopaminergic receptors, through which inotropic and vasodilator effects are mediated..$^{15}$ Beyond this inodilator effect, the drug also has a diuretic and natriuretic effect, which is mediated through renal dopamine receptors. ${ }^{16}$ Most of the different compounds that have been tested in patients with $\mathrm{CHF}$ are listed in Tables I through IV.
Table II. Oral drugs for the treatment of CHF: Neurohumoral modulators

\begin{tabular}{c} 
ACE inhibitors \\
Captopril \\
Enalapril \\
Lisinopril \\
Quinapril \\
Ramipril \\
Cilazapril \\
Perindopril \\
Zofenopril \\
Spirapril \\
Benazapril \\
Sympathetic inhibitors \\
Clonidine \\
Methyldopa \\
Guanabenz \\
Bromocriptine \\
$\alpha$-Methyl-p-tyrosine \\
Guanethidine \\
Ibopamine \\
$\alpha$-Adrenoreceptor blockers \\
Phenoxybenzamine \\
Prazosin \\
Trimazosin \\
Terazosin \\
Doxazosin \\
Bunazosin \\
Indoramin \\
Urapidil \\
$\beta$-Adrenergic blockers \\
More than 30 \\
* $\beta$-Adrenergic partial agonists \\
Xamoterol \\
Prenalterol \\
Serotonin antagonist \\
Ketanserin \\
\hline
\end{tabular}

$A C E$, Angiotensin-converting enzyme.

\section{CLASSIFICATION OF CHF PATIENTS}

The clinical syndrome of CHF represents an enormous heterogenous entity. The patient with symptoms may present in an early or relatively late stage of the disease. However, early and late are certainly not synonymous with mild as opposed to severe, since different causes of heart failure (ischemic vs nonischemic) and different stages of neurohumoral adaption and cardiac remodeling complicate the picture. Furthermore, heart failure with left ventricular hypertrophy as opposed to left ventricular dilatation requires a different approach. Also, abnormalities in systolic and diastolic cardiac function should be taken into account. Still in most trials, patients are classified according to the New York Heart Association (NYHA) classification despite the fact that its limitations are widely recognized: (1) The classification does not take into account the cause of heart failure or the drugs used at the time of assessment; 
Table III. Oral drugs for the treatment of CHF: Inotropics

c. AMP independent
Digoxin
DPI 201-106
Taurine
Carnitine
Co-enzyme Q10
$\beta$-adrenoreceptor stimulants
Ephedrine
Denopamine
Pirbuterol
Salbutamol
Terbutaline
Ibopamine
Dopamine agonists
Fenoldopam
Dopa
Ibopamine
Phosphodiesterase inhibitors
Amrinone
Milrinone
Enoximone
Imazodan
Piroximone
CI-930
Ro-13-6438
OPC-8212
Theophylline
Calcium sensitizers
Sulmazol
Pimobendan

c-AMP, Cyclic adenosine monophosphate.

(2) the lifestyle of the patient is one of the major determinants of the severity of symptoms; (3) the stage and success of compensatory mechanisms are not taken into account, and (4) above all, the classification is notoriously subjective. ${ }^{4, / 17}$ Nevertheless, since the classification judges the functional status of the patient, by definition it correlates well with the symptoms of the patient and exercise tolerance. Consequently, the patient's quality of life is fairly well related to NYHA status, but it is unrelated to the hemodynamic status and is also a poor predictor of therapeutic response to drugs or a predictor of survival after drug treatment., 18,19 Consequently, the questions, "who should be treated, how should one be treated and when should treatment start?," are still not easy to answer from a pathophysiologic point of view. Aside from difficulties in predicting the therapeutic outcome in patients with CHF, a low left ventricular ejection fraction, high concentrations of plasma norepinephrine and vasopressin, low plasma sodium concentrations, and recurrent ventricular tachycardia indicate a bad prognosis. Obviously rapid clinical deterioration is also an alarming signal. ${ }^{4,17-20}$
Table IV. Oral drugs for the treatment of CHF: Diuretics

\begin{tabular}{l}
\hline Direct \\
Thiazides \\
Loop of Henle \\
Ibopamine \\
Indirect \\
Aldosterone antagonists \\
\hline
\end{tabular}

Table v. Requirements for first-line drugs for the treatment of CHF, according to Packer

\begin{tabular}{ll}
\hline Rapid relief of symptoms & $\begin{array}{l}\text { Improve exercise tolerance } \\
\text { Improve quality of life }\end{array}$ \\
Reduce mortality & $\begin{array}{l}\text { Prevent sudden death } \\
\text { (arrhythmias) } \\
\text { Change natural history of } \\
\text { the disease (reduced } \\
\text { medication requirement, } \\
\text { hospitalizations, decline in } \\
\text { left ventricular function) }\end{array}$ \\
& Compliance with \\
Effective as monotherapy & prescription \\
\hline
\end{tabular}

\section{GOALS IN CHF TREATMENT}

CHF is a chronic, disabling, and killing disease. In modern Western society, the admission rate to hospitals because of the disease has increased more than threefold within 15 years. ${ }^{20}$ It is the most common disease in subjects over the age of 65 years. Furthermore, the disease carries a prognosis often worse than cancer: 5-year survival rates of only $50 \%$ for even mild cases and 1-year survival rates of $40 \%$ to $60 \%$ in heart failure after a myocardial infarction underline the malignant character of the disease. ${ }^{20}$ Given the prevalence of $\mathrm{CHF}$-more than 15 million people worldwide-the disease also represents a major burden on health care economics. Because the incidence of the disease is also expected to rise in the future as a result of the aging of the population and better survival is expected after myocardial infarction as a consequence of intervention with thrombolytic agents, angioplasty, and surgery, the ultimate goal will be the prevention of the disease. ${ }^{19}$ Studies to explore this option are currently underway. In the interim, our goals will be to improve the quality of life in our patients by offering therapeutic regimens that primarily provide symptomatic relief and improve exercise tolerance and that secondarily prolong life by preventing sudden death caused by arrhythmias, which are still the major cause of death in CHF (Table V). 
Table VI. Choosing drug therapy for $\mathrm{CHF}$

\begin{tabular}{|c|c|c|c|c|c|c|c|c|c|}
\hline & Diuretics & Digoxin & Enalapril & $\begin{array}{l}\text { Hydralazine } \\
\text { + nitrates }\end{array}$ & $\begin{array}{c}\text { Calcium } \\
\text { antagonists }\end{array}$ & $\begin{array}{r}\text { Phosphodieste } \\
\text { inhibitors }\end{array}$ & $\begin{array}{c}\beta \text {-Blockers } \\
\text { buffers }\end{array}$ & $\beta$-Prazosin & Ibopamine \\
\hline $\begin{array}{l}\text { Symptoms } \\
\text { (short term) }\end{array}$ & + & + & + & $?$ & $?$ & $?$ & $?$ & + & + \\
\hline $\begin{array}{l}\text { Exercise } \\
\text { (medium/long term) }\end{array}$ & $?$ & + & + & $?$ & $?$ & $?$ & + & $?$ & + \\
\hline $\begin{array}{l}\text { Mortality } \\
\quad \text { (long-term) }\end{array}$ & $?$ & $?$ & + & + & $?$ & $?$ & $?$ & $?$ & $?$ \\
\hline Monotherapy & $?$ & $?$ & $?$ & $?$ & $?$ & $?$ & + & $?$ & + \\
\hline Safe & $?$ & $?$ & $?$ & $?$ & $?$ & $?$ & $?$ & + & + \\
\hline Well tolerated & + & + & + & $?$ & $?$ & $?$ & $?$ & + & + \\
\hline
\end{tabular}

References are reviewed in Packer. ${ }^{6}$

+ , Positive effect; ?, questionable or negative effect.

\section{CHOOSING CHF DRUG THERAPY}

Before a drug is chosen for the treatment of CHF, an adequate diagnostic workup should be performed for the detection of reversible forms of heart failure such as alcohol abuse, the use of cardiodepressant drugs in subjects with preexisting symptomless left ventricular dysfunction ( $\beta$-blockers, calcium antagonists, and antiarrhythmic agents), reversible (silent) ischemia, valvular disease, arterial hypertension, anemia, myxedema, and thyrotoxicosis.

When considering the requirements for successful drug therapy for CHF as formulated by Packer $^{6}$ few drugs fullfill all criteria (Table V and VI). Diuretics not invariably improve exercise tolerance, although they do provide short-term relief of symptoms. Their effect on mortality is unknown. In the long-run they are seldom effective when given as monotherapy, and because of metabolic derangements, particularly hypokalemia, their safety is questionable, although the drugs are generally well tolerated by patients. Digoxin is effective in controlling short-term symptoms: it increases exercise capacity, and in strictly controlled trial situations, the drug appears to be surprisingly well tolerated. However, the effects on mortality are not known and long-term efficacy as monotherapy in patients who are in sinus rhythm is still much disputed as is its safety because of the proarrhythmic activity of the drug. Enalapril was the first drug for which there was a positive effect on survival in patients with endstage CHF. However, the efficacy of the drug as monotherapy in patients with symptoms has not been demonstrated. Furthermore, the effects of angiotensin-converting enzyme inhibitors on renal function are still a cause for concern. Combined treatment with hydralazine and nitrates prolongs survival in CHF. However, the effects on exercise tolerance are disappointing, and short-time symp- tomatic benefit is negligible. Although the initial enthusiasm for the hemodyamic profile of the calcium antagonists in CHF has provoked widespread research activities, the negative inotropic actions of the drugs, particularly in subjects with the most compromised left ventricular function, have mitigated this interest. Finding the right patient for the right drug is still one of the problems to be solved. Reasoning along similar lines also situates the phosphodiesterase inhibitors for the moment not in the position of first-line agents. Selection of the right patient is also still a major problem for prescribing $\beta$ blockers or $\beta$-buffers, drugs with partial agonist activity. Here again, in subjects with severe left ventricular dysfunction, the negative inotropic effects of these drugs can easily cause rapid deterioration of the clinical status of the patient. Of the $\alpha$-blockers, prazosin has been investigated extensively. This drug reduces preload and afterload, ensures rapid relief of symptoms, and has no negative inotropic activity, but positive effects on survival could not be demonstrated. This is possibly related to the rapid development of tolerance for this drug, which has been reported frequently.

\section{IS THERE A PLACE FOR IBOPAMINE IN CHF TREATMENT?}

Chemistry and receptor pharmacology. Ibopamine is the 3,4-diisobutyrylester of $\boldsymbol{N}$-methyldopamine or epinine. Esterase activity in the blood rapidly converts ibopamine into epinine, which is the active moiety of the molecule, so that ibopamine can be considered a prodrug. Animal studies have shown that epinine has dopaminergic and $\alpha$ - and $\beta$-adrenergic activities in cardiac and vascular tissue. These activities result in positive inotropic, vasodilating, natriuretic, and diuretic effects, which led the origi- 
nal investigators to study this drug in humans, particularly in patients with CHF. ${ }^{21}$

The activities of epinine on a host of cardiovascular postsynaptic, presynaptic, and ganglionic receptors do not create an easy understanding of its mechanism of action. Positive inotropic effects can be mediated by $\beta_{1}$ - and $\alpha$-adrenoreceptors, although the latter are unlikely to play a role in this respect in humans. Vasodilatation may be achieved directly by stimulation of postsynaptic $\mathrm{DA}_{1}$ - and $\beta_{2}$-adrenoreceptors and indirectly by stimulation of presynaptic $\alpha_{2}$-receptors and $\mathrm{DA}_{2}$-receptors, which are located on ganglionic cells and presynaptically, resulting in a reduction in sympathetic vasoconstrictor nerve activity. Natriuresis may result directly from a $\mathrm{DA}_{1}$ receptor-mediated mechanism on renal tubular cells controlling sodium reabsorption or more indirectly by way of a $\mathrm{DA}_{2}$-receptor-mediated mechanism that inhibits aldosterone release from the adrenal glands. Postsynaptic $\alpha_{1}$-or $\alpha_{2}$-adrenoreceptor activities could potentially lead to vasoconstriction, which can, however, be offset by the net sum of the above-mentioned vasodilator mechanisms. Consequently, ibopamine can be listed under several headings in Tables I through IV.

Hemodynamic effects. The acute hemodynamic effects of ibopamine have been reviewed recently. ${ }^{22,} 23$ In essence flow increases, afterload decreases, and arterial pressure and heart rate do not change. Transient elevations of cardiac flling pressure have been observed at higher dosages of ibopamine $(>200 \mathrm{mg}$ ). The mechanism of this phenomenon is not fully understood. Although the initial idea was that it could be explained by $\alpha$-adrenoreceptor-mediated vasoconstriction, this hypothesis is not very likely, since pretreatment with the $\alpha$-adrenoreceptor antagonist prazosin does not prevent this response. ${ }^{24}$

The neurohumoral counterregulations after an insult to the myocardium lead to elevated concentrations of plasma renin, aldosterone, and norepinephrine. After treatment with ibopamine, the elevated levels of these neurohumoral parameters decrease. $^{25-28}$ Thus if one pieces together the profile of hemodynamic, renal, and neurohumoral abnormalities in CHF and the actions of ibopamine on these parameters, a mirror image emerges. However, this does not necessarily imply long-term clinical efficacy of the drug in the areas of improved quality of life or survival.

Etficacy. A review of several noncomparative and comparative studies of ibopamine shows that the drug maintains its hemodynamic improvements established in single-dose studies without significant alteration in blood pressure and heart rate. ${ }^{10}$ The lack of the development of tolerance was recently reported in two studies. ${ }^{29,30}$ Dei Cas et al. ${ }^{29}$ followed the hemodynamic response to ibopamine when given on a short-term basis at the beginning of treatment and after long-term therapy in 15 patients. Hemodynamic responses to ibopamine at $0,1,2,3,8$, and 12 months of therapy were similar. Reffo et al. ${ }^{30}$ evaluated ibopamine after 3 months of treatment in 15 patients compared with placebo under double-blind conditions by means of invasive hemodynamic monitoring. In both evaluations, ibopamine improved hemodynamic response to the same extent before and after 3 months of treatment, so that the development of tolerance could also not be demonstrated in this study.

The clinical efficacy of ibopamine has been demonstrated for as long as 1 and 2 years. Both in shortand long-term comparative studies, ibopamine, 100 $\mathrm{mg}$, three times daily, improves disability scores, exercise tolerance, and left ventricular function during exercise. These initially encouraging data have been confirmed in double-blind, placebo-controlled studies and in comparative studies with digoxin and diuretics. In a relatively short-term study (4 weeks) in 58 patients with mild-to-moderate CHF stabilized on digoxin and diuretics, in half the patients ibopamine was substituted for digoxin in a double-blind, randomized way. Ibopamine appeared to be as effective as digoxin in this study as judged by clinical symptom and disability scores, echocardiographic parameters, left ventricular function, and exercise tolerance as measured by bicycle ergometry. ${ }^{31}$

Three large, well-controlled, randomized, and double-blind trials have been reported only in abstract form to date. ${ }^{32-34}$ In a 4-week study, ibopamine, 200 mg, two times daily, was compared with digoxin and placebo in 60 untreated patients with NYHA classes I and II. Changes in body weight, peripheral edema, fatigue, and dyspnea ratings and patients' questionnaire scores were evaluated. ${ }^{32}$ Body weight decreased by $3.5,1.7$, and $0.9 \mathrm{~kg}$ in the ibopamine, digoxin, and placebo groups, respectively. Mean edema scores decreased from 1.9 to $0.1,1.5$ to 0.3 , and 1.5 to to 1.0 , respectively. Total mean patient questionnaire scores decreased from 6.2 to $1.1,5.3$ to 2.7 , and 4.7 to 4.6 in the three groups, respectively. In another study of 80 patients in NYHA classes II and III treated with digoxin and diuretics, the subjects were randomly allocated to receive placebo or ibopamine, $200 \mathrm{mg}$, three times daily. ${ }^{33}$ Sixty of these patients were followed up for 4 months and 21 were followed for 6 months. The last group was also included in an analyis of exercise tolerance. The mean exercise time was greater for the ibopamine-treated group than for the 
placebo-treated group at 1,2, and 6 months (placebo, minus 0.35 minute, and ibopamine, plus 1.02 minute, $p<0.05$ ). After 6 months of treatment, $70 \%$ of ibopamine-treated patients improved compared with baseline versus $40 \%$ of the patients receiving placebo. Improvement in symptom score was greater for the ibopamine-treated patients than for placebotreated patients at 1,2 , and 6 months $(p<0.05)$. In a double-blind study of 247 patients in NYHA classes I and II, placebo $(n=63)$, hydrochlorothiazide, 25 $\mathrm{mg}$, two times daily $(n=60)$, ibopamine, $200 \mathrm{mg}$, two times daily $(n=61)$, or ibopamine plus hydrochlorothiazide $(n=63)$ were compared for 8 weeks. ${ }^{34,43}$ All active treatments were more effective than placebo in the reduction of body weight and edema. Patients withdrawn from treatment because of insufficient therapeutic response included 15 on placebo, 3 on ibopamine, 2 on ibopamine plus hydrocholothiazide, and 2 on hydrochlorothiazide alone. All treatment groups had a similar incidence of adverse events, although there was a greater incidence of hypokalemia in hydrochlorothiazide-treated patients. Although further double-blind, controlled studies are required to verify the long-term (more than 12 months) beneficial effects of ibopamine, it already appears that this inodilator is potentially an attractive addition to the treatment of CHF as a substitute for digoxin or diuretics or as an adjunct to these remedies either alone or in combination. This supposition was confirmed recently in several larger trials. ${ }^{35-38}$

Safety and side effects. Noncardiovascular adverse effects are mainly from gastrointestinal origin, as judged from a large postmarketing survey in Italy in 515 patients, who were treated for a mean period of $71 / 2$ months. ${ }^{39}$ Gastrointestinal symptoms occurred in $3.1 \%$ of patients, and complaints ranging from anxiety to headache, rash, or tremor were between $0.2 \%$ and $0.6 \%$. Because positive inotropic drugs may exert arrhythmogenic properties, special attention was paid to arrhythmias in patients treated with digoxin or ibopamine. Arrhythmia was reported in $5.6 \%$ of patients receiving ibopamine versus $9.4 \%$ of patients receiving digoxin. The issue of potential proarrhythmogenic action of ibopamine was further addressed in a double-blind, multicenter study of 97 patients (NYHA classes II and III), who were treated with ibopamine, $100 \mathrm{mg}$, three times daily, for 7 days in a random, crossover design with placebo. Any complex ventricular arrhythmias under basal conditions were not present at baseline. While on placebo and ibopamine, all patients were subject to 48 hours of Holter monitoring. ${ }^{40}$ The mean number per hour of ectopic supraventricular beats was 26 after ibo- pamine and 22 after placebo $(p<0.05)$. The complexity of ectopic supraventricular beats did not change with the treatment regimen. The mean number of ectopic ventricular beats was 31 after ibopamine and 30 after placebo $(p<0.05)$. The distribution of the patients among the Lown classification in the 48 hours of ibopamine and placebo was also not different. None of the patients experienced sustained ventricular tachycardia. Ventricular repolarization behavior was also not affected. Thus apparently in this group of patients, ibopamine appeared to be free of proarrhythmogenic activity despite its positive inotropic action. In another study 25 patients (NYHA classes II and III) were studied during 7 days of placebo, 7 days of ibopamine ( $100 \mathrm{mg}$, three times daily) and ibopamine ( $200 \mathrm{mg}$, three times daily) sequentially by means of 48 hours of Holter monitoring. ${ }^{41}$ No significant differences between the data collected under the three conditions were found. Although statistically not significant, the number of supraventricular beats and ventricular premature contractions was lower for ibopamine than for placebo. Thus it appears that ibopamine is well tolerated by patients and is free of proarrhythmic activity. Side effects do not limit its prescription in patients with symptoms of CHF.

Survival. Although data from a formal survival trial with ibopamine are unavailable today, given that its efficacy is comparable with digitalis and diuretics in patients with $\mathrm{CHF}$, and considering its excellent tolerability and safety, it is quite likely that there is a place for ibopamine as a first-line agent in the treatment of CHF. Ibopamine could serve as a substitute for digitalis or diuretics as monotherapy in NYHA classes I and II or as an adjunct to diuretics or digitalis in NYHA classes II and III as a step before vasodilator therapy is started. Examination of the available published and unpublished reports in which survival was a coincidental observation and not the primary end point suggests that ibopamine may also have a beneficial effect on lifespan in patients with moderate or severe heart failure. ${ }^{42}$

\section{REFERENCES}

1. Lipkin DP, Poole-Wilson PA. Treatment of chronic heart failure: a review of recent drug trials. Br Med J 1985;291:9936.

2. Braunwald E. Newer positive inotropic agents. Circulation 1986;73:III1-III3.

3. Timmis A. Modern treatment of heart failure; diuretics are often enough, but do not overuse. $\mathrm{Br}$ Med J 1988;297:83-4.

4. Cohn JN. Current therapy of the failing heart. Circulation 1988;78:1009-107.

5. Packer M. Vasodilator and inotropic drugs for the treatment of chronic heart failure: distinguishing hype from hope. J Am Coll Cardiol 1988;12:1299-317.

6. Packer M. Therapeutic options in the management of chronic 
heart failure. Is there a drug of first choice? Circulation 1979;1:198-204.

7. Anonymous. Enoximone. Lancet 1988;1:1085-6.

8. The Captopril-Digoxin Multicenter Research Group. Comparative effects of captopril and digoxin in patients with mild to moderate heart failure. JAMA 1988;259:539-44.

9. DiBianco R, Shabetai R, Kostuk W, Moran J, Schlant R, Wright $R$, for the Milrinone Multicenter Trial Group. A comparison of oral milrinone, digoxin and their combination in the treatment of patients with chronic heart failure. N Engl J Med 1989;320:677-83.

10. Lee DCS, Johnson RA, Bingham JB, et al. Heart failure in out-patients: a randomized trial of digoxine versus placebo. $\mathrm{N}$ Engl J Med 1982;306:699-705.

11. Guyatt GH, Sullivan MJJ, Fallon EL, et al. A controlled trial of digoxine in congestive heart failure. Am $J$ Cardiol 1983;61:371-5.

12. The German and Austrian Xamoterol Study Group. Doubleblind placebo controlled comparison of digoxin and xamoterol in chronic heart failure. Lancet 1988;i:489-93.

13. Man in 't Veld AJ. Is there a place for ibopamine in the treatment of congestive heart failure? Cardiovasc Drug Ther 1989;3:1065-9.

14. Opie LH. Inodilators. Lancet 1986;1:1336.

15. Casagrande C, Santangelo F, Saini C. Synthesis and chemical properties of ibopamine and of related esters of $N$-substituted dopamines. Arzneim-Forsch 1986;36:291-303.

16. Casagrande C, Merlo L, Ferrini R, Miragoli G, Semeraro C. Cardiovascular and renal action of dopaminergic prodrugs. $J$ Cardiovasc Pharmacol 1989;14:S40-S60.

17. Gorlin R. Treatment of congestive heart failure: where are we going. Circulation 1987;75:IV108-IV111.

18. Packer M. Neurohumoral interactions and adaptations in congestive heart failure. Circulation 1988;77:721-30.

19. Cohn JN. Plasma norepinephrine as a guide to prognosis in patients with chronic congestive heart failure. N Eng J Med 1984;311:819-823.

20. Packer M. Prolonging life in patients with congestive heart failure: the next frontier. Circulation 1987;75:IV1-IV3.

21. Casagrande C, Castelnovo P, Cerri O, Ferrini R, Merlo L, et al. Ibopamine: investigation of metabolism and pharmacokinetics in relationship to pharmacodynamics. Proceedings of the 8th International Symposium on Medical Chemistry, Uppsala, 1984. Stockholm: Swedish Pharmaceutical Press, 1985:481-91.

22. Henwood J, Todd PA. Ibopamine, a preliminary review of its pharmacodynamic and pharmacokinetic properties and therapeutic efficacy. Drugs 1988;36:11-31.

23. Iopez-Sendon J. Hemodynamic effects of ibopamine in congestive heart failure. Cardiovasc Drug Ther 1989;3:1029-41.

24. Rocke DA, Naidoo DP, Mahomedy AE, Chetty S, Mitha AS. Hemodynamic effects of ibopamine with prazosin in congestive heart failure [Abstract]. 61st American Association, Washington, D.C., 1988.

25. Inecrti PL, Badalmenti S, Lorenzano E, et al. Humoral and renal effects of ibopamine in normal subjects. Arzneim-Forsch 1986;36:405-7.

26. Rolandi E, Marchetti G, Franceschini R, et al. Inhibition of prolactin and aldosterone secretion by the dopamine derivative ibopamine. Eur J Clin Pharmacol 1986;29:629-30.

27. Nakano T, Morimoto Y, Katuta Y, et al. Acute effects of ibopamine hydrochloride on hemodynamic plasma catecholamine levels, renin activity, aldosterone, metabolism and blood gasses in patients with severe congestive heart failure. Arzneim-Forsch 1986;36:1829-33.
28. Rajfer SI, Rossen JD, Douglas FL, Goldberg LI, Karrison T. Effects of long-term therapy with oral ibopamine on resting hemodynamics and exercise capacity in patients with heart failure: relationship to the generation of $N$-methyldopamine and to plasma norepinephrine levels. Circulation 1986;73:7408.

29. Dei Cas L, Metra M, Nodari S, Diva S, Manca C, Visioli O. Lack of tolerance development during chronic ibopamine administration to patients with congestive heart failure. Cardiovasc Drug Ther 1988;2:221-9.

30. Reffo GC, Gabelline A, Forattini C, et al. Double-blind acute haemodynamic invasive evaluation in congestive heart failure before and after sustained treatment with ibopamine. Curr Ther Res 1988;44:723-30.

31. Cavalli A, Riva E, Schleman M, Abbondati G, Euccella LM, Smith-Kline and French Ibopamine Group. Ibopamine as a substilute for digitalis in patients with congestive heart failure on chronic digitalis therapy. Int $J$ Cardiol 1989;22:381-7.

32. Clowdus B, Greither A, Tiggeman R, Moore A, Wilta B. Comparison of ibopamine with placebo and digoxin in chronic mild congestive heart failure. [Abstract 1071] Tenth World Congress of Cardiology, Washington D.C., 1986.

33. Kayanakis JG, Schbath J, Schlaman MM, Moore AL, Hosutt JA. Comparison of ibopamine and placebo in the treatment of chronic congestive heart failure NYHA class II III. Second Cardiovascular Pharmacotherapy International Symposium, San Francisco, Calif., 1987.

34. Clowdus B, Schaeffer J, Tiggeman R, Schleman M, Moore A, Hosutt J, Nagle B. Effects of ibopamine, hydrochlorothiazide or placebo on signs and symptoms of mild chronic congestive heart failure. Fifth Joint Meeting of the Working Groups of the European Society of Cardiology and Symposium on 'Ten Years Balloon Dilatation in Cardiovascular Disease Santiago de Compostela, Spain, 1987.

35. Alicandri C, Fariello R, Boni E, Zaninelli A, Muiesan G. Ibopamine vs. digoxin in chronic heart failure: a double-blind, cross-over study. J Cardiovasc Pharmacol 1989;14-8:S77-S83.

36. Condorelli M, Mattioli $\mathrm{G}$, Caponetto $\mathrm{S}$, et al. The long-term efficacy of ibopamine in treating patients with severe heart failure: a multicentre investigation. J Cardiovasc Pharmacol 1989;14-8:S83-S93.

37. Rolandi E, Sabino F, Cantoni V, Ghirardi P, Marchetti GV, Cicchetti $V$. Long-term therapy of chronic congestive heart failure with ibopamine: a multicenter trial. J Cardinvasc Pharmacol 1989;14-8:S93-S104.

38. Dei Cas L, Metra M, Nodari S Visioli O. Efficacy of ibopamine treatment in patients with advanced heart failure: purpose of a new therapeutic scheme with multiple daily administrations. J Cardiovasc Pharmacol 1989;14-8:S111-S8.

39. Sher D, Ferrari V. Ibopamine post-marketting surveillance. First report from a parallel-cohorts survey ongoing since April 1st, 1985. Arzneim-Forsch 1987;37:873-99.

40. Furlanello et al. Influence of dopamine on heart rate and arrhythomogenic pattern in patients with congestive heart failure. Giornale Italiano di Cardiologia 1990 [in press].

41. Caponetto S, Terrachini Canale C, Bruzzone F, Licciardello L, Marchetti GV. Absence of proarrhythmic effects of ibopamine in patients with congestive heart failure. J Cardiovasc Pharmacol 1989;14-8:S104-S11.

42. Taylor SH. Ibopamine and lifespan in heart failure. Cardiovasc Drugs Ther 1989;3:1059-65.

43. Kleber F,X, Thyroff Friesinger U, Treatment of mild chronic congestive heart failure with Ibopamine, Hydrochlorthiazide, Ibopamine plus Hydrochlorthiazide or Placebo. Cardiology 1990;77(suppl 5). 